\title{
Deep sedation for colonoscopy is unnecessary and wasteful
}

\author{
David Pace MD, Mark Borgaonkar MD MSc
}

Cite as: CMAJ 2018 February 12;190:E153-4. doi: 10.1503/cmaj.170953

D eep sedation for routine colonoscopy is of marginal benefit, costs more and may negatively affect safety and quality compared with mild-to-moderate sedation with traditional sedatives. The increasing use of deep sedation for colonoscopy in North America is a trend that should be curtailed to reduce unnecessary spending associated with procedures, and needless intervention that may cause harm.

In many countries, a large proportion of colonoscopies are performed with little or no sedation. According to a national audit in the United Kingdom, $0.4 \%$ of colonoscopies were performed using propofol, a short-acting drug that induces a state of deep sedation, and $10.7 \%$ were performed without sedation. ${ }^{1}$ Conversely, a restrospective cohort study using administrative claims data in the United States found that the use of propofol and anesthesia for colonoscopy occurred in about $35 \%$ of cases. ${ }^{2}$ In Ontario, the use of propofol for colonoscopy increased from $19 \%$ in 2005 to $44 \%$ in $2012 .{ }^{3}$ Reasons for the increase in deep sedation included patient preference, endoscopist preference and improved efficiency gained from faster patient recovery.

Although numerous studies have shown the safety of propofol administration directed by endoscopists, it is usually given with anesthesia assistance in North America. Although successful efforts have been made to encourage nonanesthesiologists to administer this drug in parts of Europe, similar attempts have been largely unsuccessful in the US and Canada because of concerns about medico-legal risks, regulatory obstacles and financial disincentives. ${ }^{4}$

Also, in Canada, health care facilities may have a financial incentive to use anesthesiologists in endoscopy units as they are paid through provincial health plans, whereas nursing staff are paid through a facility's budget. In many private endoscopy centres in Canada, part of the anesthesiologist's fee is used to support the centre. The cost of colonoscopy in Ontario was $\$ 346$ in 2014. This included endoscopist fees, equipment costs, drugs and manpower, but excluded reprocessing, pathology fees and other indirect costs. When sedation was given by an anesthesiologist, the cost rose to $\$ 498$ (Dr. Nancy Baxter, Ontario Ministry of Health and Long-term Care, Toronto: personal communication, 2014). This included the added costs of monitoring equipment and propofol.

In the US, charges for anesthesia care are substantially higher than in Canada. A study conducted between 2003 and 2009 in the

\section{KEY POINTS}

- The increasing use of deep sedation for routine colonoscopy in North America is a trend that should be curtailed.

- Deep sedation is of marginal benefit.

- Deep sedation costs more than traditional procedural sedation.

- Use of deep sedation may negatively affect safety and quality.

US estimated that the annual cost for anesthesia services for upper and lower gastrointestinal endoscopies was $\$ 1.1$ billion. ${ }^{5}$ However, the researchers involved in this study noted that most patients were healthy and did not require anesthesia assistance. If propofol is administered by nonanesthesiologists, the costs for a colonoscopy decrease substantially. An analysis published in 2012 suggested that a savings of $\$ 3.2$ billion could be achieved over a 10 -year period in the US. ${ }^{6}$

There is no convincing evidence that the level of sedation affects the cecal intubation rate or the adenoma detection rate. However, there is indirect evidence that deep sedation may adversely affect quality. A meta-analysis of randomized controlled trials (RCTs) involving 2518 patients showed no difference in cardiopulmonary adverse events when comparing propofol with traditional agents. ${ }^{7}$ Data from large administrative databases, although inconsistent, suggest that there may be an increased risk of uncommon, but serious, events associated with the use of an anesthesiologist during colonoscopy. An observational study of administrative data from more than 3 million patients found that the use of anesthesia services was associated with a $13 \%$ increase in complications within 30 days, including perforation, hemorrhage, pneumonia and stroke. ${ }^{2}$ A study involving adult participants undergoing outpatient colonoscopy in Ontario found that anesthesia assistance was associated with an increased risk of aspiration pneumonia but was not associated with perforation or splenic injury. ${ }^{8}$ Anesthesiologists will typically use propofol sedation if attending a colonoscopy.

Aside from serious events, deep sedation may limit the ability of the operator to use best technique. Although earlier, smaller studies reported conflicting results, a recent multicentre RCT involving patients undergoing colonoscopy for the first time in six hospitals in the Republic of Korea reported that dynamic 
position change on withdrawal results in a higher detection rate for adenoma compared with static left-lateral positioning. ${ }^{9}$ Yet, this technique is less likely to be used in deeply sedated patients who cannot turn themselves.

The use of water exchange as opposed to air during colonoscope insertion has been shown to not only decrease sedation usage, but also to improve adenoma detection rates. ${ }^{10}$ Because deeply sedated patients have decreased sphincter tone, the chance of fecal incontinence is more likely and may dissuade some from using water in this setting.

Deep sedation may also hinder learning for physicians training in endoscopy, who will not be alerted to poor technique by patients vocalizing discomfort. This lack of feedback may impede skills development and promote suboptimal and potentially unsafe colonoscopy. Proper colonoscopy technique is critical. Participation in hands-on colonoscopy courses has been shown to improve adenoma detection rates and reduce sedation requirements for practising endoscopists. ${ }^{11}$

There are some benefits of using propofol, including a quicker onset of action and a shorter recovery time compared with traditional sedation. Patient satisfaction with propofol-based sedation is either equivalent to or slightly better than a benzodiazepine/ narcotic combination. ${ }^{12}$ It is also highly desired by apprehensive patients who wish to be unaware during the procedure. However, in most cases, deep propofol sedation should not be administered routinely. It is of marginal benefit, costs substantially more and may negatively affect safety and quality. We owe it to patients and to the Canadian taxpayer to stop the routine use of this unnecessary practice.

\section{References}

1. Gavin DR, Valori RM, Anderson JT, et al. The national colonoscopy audit: a nationwide assessment of the quality and safety of colonoscopy in the UK. Gut 2013;62:242-9.

2. Wernli KJ, Brenner AT, Rutter CM, et al. Risks associated with anesthesia services during colonoscopy. Gastroenterology 2016;150:888-94.

3. Bielawska B, Tinmouth J, Paszat LF. Rising use of anesthesiology assistance for outpatient colonoscopy in Ontario: an update. Can J Gastroenterol 2015;29:83A (A5).

4. Rex DK. Endoscopist-directed propofol. Gastrointest Endosc Clin N Am 2016; 26:485-92.

5. Liu H, Waxman DA, Main R, et al. Utilization of anesthesia services during outpatient endoscopies and colonoscopies and associated spending in 2003-2009. JAMA 2012;307:1178-84.

6. Hassan C, Rex D, Cooper G, et al. Endoscopist-directed propofol administration versus anesthesiologist assistance for colorectal cancer screening: a costeffectiveness analysis. Endoscopy 2012;44:456-64.

7. Wadhwa V, Issa D, Garg S, et al. Similar risk of cardiopulmonary adverse events between propofol and traditional anesthesia for gastrointestinal endoscopy: a systematic review and meta-analysis. Clin Gastroenterol Hepatol 2017;15: 194-206.

8. Bielawska B, Hookey L, Sutradhar R, et al. Anesthesia assistance in outpatient colonoscopy and risk of aspiration pneumonia, bowel perforation, and splenic injury. Gastroenterology 2018;154:77-85.e3.

9. Lee SW, Chang JH, Ji JS, et al. Effect of dynamic position changes on adenoma detection during colonoscope withdrawal: a randomized controlled multicenter trial. Am J Gastroenterol 2016;111:63-9.

10. Hafner S, Zolk K, Radaelli F, et al. Water infusion versus air insufflation for colonoscopy. Cochrane Database Syst Rev 2015;(5):CD009863.

11. Kaminski MF, Anderson J, Valori R, et al. Leadership training to improve adenoma detection rate in screening colonoscopy: a randomised trial. Gut 2015;0:1-9.

12. McQuaid KR, Laine L. A systematic review and meta-analysis of randomized, controlled trials of moderate sedation for routine endoscopic procedures. Gastrointest Endosc 2008;67:910-23.
Competing interests: None declared.

This article has been peer reviewed.

Affiliations: Departments of Surgery (Pace) and of Medicine (Borgaonkar), Memorial University, St. Johns, NL
Contributors: David Pace drafted the work. Both of the authors made substantial contributions to the conception and design of the work; were involved with the acquisition, analysis and interpretation of data for the work; revised it critically for important intellectual content; gave final approval of the version to be published; and agreed to be accountable for all aspects of the work in ensuring that questions related to the accuracy or integrity of any part of the work are appropriately investigated and resolved.

Correspondence to: David Pace, pacedavid@ me.com,dpace@mun.ca 